\title{
Estratégias Utilizadas Pelos Profissionais da Enfermagem na Abordagem à Criança Hospitalizada
}

\author{
Ana Cláudia Seus Falkeㄹ, Viviane Marten Milbrath², Vera Lucia Freitag
}

\begin{abstract}
RESUMO
Introdução: A hospitalização infantil pode desenvolver na criança e família sentimentos confusos e dicotômicos como, por exemplo, morte e cura, tristeza e alegria, medo e confiança, tornando o hospital um ambiente de experiências dolorosas e de grande relevância para toda a vida, por isso a importância de os profissionais de enfermagem desenvolver estratégias que minimizem estes sentimentos. Objetivo: Conhecer as estratégias utilizadas pelos profissionais da enfermagem para abordar a criança hospitalizada. Método: Estudo descritivo e exploratório, com abordagem qualitativa, realizado no período de junho a dezembro de 2015 na pediatria de um Hospital Escola do Sul do Rio Grande do Sul/Brasil, com oito profissionais da equipe de enfermagem, sendo três enfermeiros e cinco técnicos de enfermagem. O estudo teve aprovação do Comitê de Ética em Pesquisa da Faculdade de Medicina da Universidade Federal de Pelotas, aprovado sob o número: 1.195.440, em 24/8/2015. Resultados: Pode-se observar que a equipe de enfermagem utiliza o ato de brincar, bem como o diálogo, a fim de abordar a criança no ambiente hospitalar, procurando criar vínculo e minimizar o trauma que pode causar uma internação hospitalar. Conclusões: Torna-se fundamental que a equipe de enfermagem lance mão do uso de estratégias, como o brinquedo e o diálogo, no intuito de diminuir o impacto de uma internação hospitalar para as crianças, favorecendo um cuidado humanizado não somente para a criança, mas também para a família.
\end{abstract}

Palavras-chave: Cuidado da criança. Hospitalização. Cuidado de enfermagem. Família.

\section{STRATEGIES USED BY NURSING PROFESSIONALS IN THE APPROACH TO THE HOSPITALIZED CHILD}

\section{ABSTRACT}

Introduction: Childhood hospitalization can develop confused and dichotomous feelings in the child and family, such as death and healing, sadness and joy, fear and trust, thus making the hospital an environment of painful experiences of great importance for life, thus, it is important that nursing professionals develop strategies that minimize these feelings. Objective: To know the strategies used by nursing professionals to approach hospitalized children. Method: Descriptive and exploratory study, with qualitative approach, carried out in the period from June to December 2015, in the pediatrics of a Teaching Hospital in the south of Rio Grande do Sul/Brazil, with eight nursing professionals (three nurses and five nursing technicians). The study was approved by the Research Ethics Committee of the College of Medicine of the Federal University of Pelotas, under number 1.195.440,08/24/2015. Results: The nursing team uses playful actions, as well as the dialogue in order to approach the child in the hospital environment, in order to create a bond and minimize the trauma that hospitalization can cause. Conclusions: The nursing team needs to use strategies such as toys and dialogue in order to reduce the impact of hospitalization for children, favoring a humanized care not only for the child, but also for the family.

Keywords: Child care. Hospitalization. Nursing care. Family.

\footnotetext{
Especialista em Auditoria em Serviço de Enfermagem. Enfermeira. Universidade Federal de Pelotas (UFPel). anaclaudiafalke@gmail.com

2 Professora da Escola de Enfermagem e do Programa de Pós-Graduação em Enfermagem da Universidade Federal de Pelotas (FEn/PPGEnf/UFPel). Doutora em Enfermagem. Enfermeira. vivianemarten@hotmail.com

${ }^{3}$ Doutoranda em Enfermagem pelo Programa de Pós-Graduação em Enfermagem da Universidade Federal do Rio Grande do Sul (PPGEnf/UFRGS). Mestre em Ciências da Saúde. Enfermeira. Bolsista pela Coordenação e Aperfeiçoamento de Pessoal de Nível Superior (Capes). verafreitag@hotmail.com
} 


\section{INTRODUÇÃO}

O ser humano, independentemente de sua idade, ao ser hospitalizado é obrigado a romper com suas atividades sociais e diárias, afastando-se de seu cotidiano e das pessoas que o rodeiam. Assim, a pessoa, ao ser internada, entra em um ambiente não familiar, o que the deixa vulnerável, amedrontada, angustiada e depressiva (LEE; CHAI; ISMAIL, 2012).

Segundo os mesmos autores, a hospitalização infantil pode desenvolver na criança e na família sentimentos confusos e dicotômicos como, por exemplo, morte e cura, tristeza e alegria, medo e confiança, tornando o hospital um ambiente de experiências dolorosas e de grande importância para toda a vida.

A hospitalização representa para a criança uma situação adversa de todas já vivenciadas, pois sua rotina é modificada. É um processo estressante e ameaçador, quando a criança afasta-se do convívio familiar e social e passa a conviver com pessoas estranhas, às quais ela não está acostumada, sendo submetida a procedimentos invasivos e dolorosos, além de ter suas atividades recreativas parcialmente interrompidas (GOMES; NÓBREGA, 2015).

As dificuldades que as crianças enfrentam durante a internação se devem, essencialmente, ao medo do desconhecido ou às situações desagradáveis sofridas por elas em hospitalizações anteriores. Isso Ihes causa temor, levando-as a crer que todas as enfermeiras ou pessoas vestidas de branco lhes causarão sensações dolorosas (GOMES; NÓBREGA, 2015; RIBEIRO, 2015).

Essa experiência, muitas vezes, deixa a criança ansiosa, insegura e com medo, principalmente quando não é preparada para a hospitalização e para a realização de procedimentos invasivos, como a punção venosa, o que proporciona o aumento dos sentimentos de medo, estresse e ansiedade que são expressos por meio do choro, raiva e até possíveis agressões (GOMES; NÓBREGA, 2015).

As crianças, às vezes, não compreendem, em virtude de seu pensamento fantasioso e egocêntrico, a hospitalização e o porquê de estarem ali ou o que irá acontecer com elas e, então, acabam entendendo a hospitalização como uma experiência enigmática e aterrorizante e percebem o hospital com um local estranho, de torturas e suplícios, de agressões físicas com intenção punitiva, de solidão, de tristeza e de muitas saudades. Para elas, o hospital é um lugar muito desagradável, onde é proibido brincar e não são ouvidas ou atendidas suas necessidades (SOUZA et al., 2012).
Neste sentido, a literatura relata que algumas manifestações da criança são comuns durante a hospitalização: regressões, diminuição no ritmo de desenvolvimento, dependência, desordens no padrão do sono, agressividade, inapetência, apatia, estado depressivo, transtorno de comportamento e fobias (HOSTERT; ENUMO; LOSS, 2014).

Sob essa ótica, encontra-se na abordagem lúdica uma maneira terapêutica de tornar a hospitalização menos traumatizante (BRITO et al., 2009). Pesquisas indicam que quando a criança é acometida por uma enfermidade as brincadeiras podem garantir seu equilíbrio emocional, além de proporcionar um melhor enfrentamento da sua condição atual (SOUZA et al., 2012).

Nesta premissa, o enfermeiro deve ser capaz de desenvolver uma abordagem adequada para que a criança e a família sintam-se acolhidas, mediando os saberes necessários ao cuidado à criança no hospital. Nessa perspectiva, a equipe de enfermagem atua na promoção, fato que permite o estabelecimento de um vínculo terapêutico afetivo, no qual se valoriza a singularidade e a historicidade da criança e sua família.

Destarte, o objetivo deste estudo foi conhecer as estratégias utilizadas pelos profissionais da enfermagem para abordar a criança hospitalizada.

\section{MÉTODO}

Trata-se de um estudo descritivo e exploratório à luz de uma abordagem qualitativa, realizado no período entre setembro e dezembro de 2015 na pediatria de um Hospital Escola do Sul do Rio Grande do Sul/Brasil.

Os participantes do estudo foram oito profissionais da equipe de enfermagem, sendo três enfermeiros e cinco técnicos de enfermagem, identificados por codinomes: E1 e E2, respectivamente para Enfermeiro, e TE1 e TE2, respectivamente para Técnico em Enfermagem.

A seleção dos participantes foi feita por convite, e, após, sorteio, sendo selecionados enfermeiros e técnicos de enfermagem que estavam trabalhando no setor no mínimo há um ano, e, portanto, familiarizados e integrados com o mesmo. Também era critério de exclusão estar de férias ou licença-saúde no período da coleta das informações. Os participantes assinaram o Termo de Consentimento Livre e Esclarecido, e, após, responderam à entrevista semiestruturada.

As entrevistas foram realizadas em uma sala reservada, no próprio hospital, gravadas e transcritas logo após a sua realização. Para a interpretação das 
informações adotou-se a análise temática de Minayo (2012), que consiste em três etapas: pré-análise, exploração dos dados e tratamento dos resultados obtidos e interpretação.

O estudo teve aprovação Comitê de Ética em Pesquisa da Faculdade de Medicina da Universidade Federal de Pelotas para avaliação, sendo aprovado sob o número 1.195 .440 , em 24/8/2015.

\section{RESULTADOS E DISCUSSÃO}

Os participantes da pesquisa foram todas muIheres com a faixa etária média de 52 anos e uma média de 18 anos de enfermagem. Quanto à categoria profissional, três eram enfermeiras e cinco técnico-auxiliares de enfermagem.

A partir da interpretação das informações, emergiu uma unidade temática: as estratégias utilizadas pelos profissionais da enfermagem para abordar a criança hospitalizada.

\section{As Estratégias Utilizadas Pelos \\ Profissionais da Enfermagem Para \\ Abordar a Criança Hospitalizada}

Ao dar voz aos participantes da pesquisa sobre a maneira como abordam a criança hospitalizada, foi possível perceber que os profissionais compreendem que o estabelecimento do vínculo de confiança entre a enfermagem e a criança/família é fundamental na abordagem, como se pode perceber nas falas que seguem.

Estabeleço um vínculo de confiança com a criança (TE1).

Conquistá-la e formar um vínculo sempre é muito importante (TE2).

Conquistar a confiança é uma boa técnica, pois facilita os procedimentos realizados(TE4).

Conquista-se ela; procuro conversar e estabelecer confiança (E2).

Pode se perceber durante a entrevista que as participantes demonstram uma preocupação com a formação do vínculo e a conquista da confiança da criança e família para realizarem a abordagem de forma que obtenham sucesso nos procedimentos realizados e no cuidado.

A fim de melhorar a qualidade do cuidado prestado para a criança, Xavier et al. (2013) afirmam que a equipe de enfermagem dispõe de instrumentos capazes de proporcionar vivências com novos objetivos, sentimentos, sensações e atividades não ameaçadoras, que auxiliam na formação de vínculo com um elo de confiança entre o profissional e a criança.

É fundamental possibilitar à criança um espaço para que ela possa expressar seus sentimentos a respeito das experiências traumáticas por meio do vínculo afetivo estabelecido pela equipe de enfermagem (MARQUES et al., 2014), posto que, durante a hospitalização, a criança é afastada do seu ambiente e de suas atividades rotineiras. Destarte, se o cuidado oferecido pelos profissionais for apropriado, os sentimentos negativos, como o medo e a ansiedade, podem ser minimizados (FARIAS et al., 2017).

A formação de vínculos entre a família e a equipe de enfermagem desde o início da internação da criança, é imprescindível e tem a finalidade de atenuar o estresse provocado pela hospitalização. 0 apoio emocional oferecido à criança hospitalizada pelo acompanhante constitui-se em ferramenta facilitadora da recuperação (PACHECO et al., 2013).

Para o estabelecimento do vínculo e da confiança, os participantes utilizam estratégias, e, dentre elas, destaca-se o brincar.

Com muito carinho, muitos sorrisos [...] brincando (TE3).

Procuro descontrair, brincar [...] se for menor mostra-se figuras e desenhos colados no posto de enfermagem (TE2).

Brinco com todo mundo, quando existe oportunidade (TE1).

Quando a criança é pequeninha não entende, brinco com ela (TE1).

Os maiores deixo brincarem no computador (E3).

Como se trata de criança a gente tenta descontrair, brincar, o que ajuda a abordar no primeiro contato com a criança e os pequenos, lactentes, mostramos os móbiles e figuras no posto (E1).

As falas demonstram que, indiferentemente da idade, o brincar é considerado uma estratégia de aproximação entre o profissional e a criança; além disso, os participantes relatam a relevância de estabelecer contato respeitando/observando a faixa etária de acordo com o desenvolvimento da criança. Também destaca-se a importância do carinho e do sorriso, brincando, descontraindo e, assim, adquirindo confiança e criando vínculos. 
Segundo Magnabosco, Tonelli e Souza (2008), para abordar a criança deve-se levar em conta sua faixa etária, planejando a abordagem com base no seu desenvolvimento e nível de conhecimento existente.

Nas entrevistas, a maioria relata usar o brinquedo como uma maneira de criar laços com a criança. Paladino, Carvalho e Almeida (2014) ressaltam que, dentre as formas de interagir com o meio da criança, encontra-se na brincadeira uma forma de relacionar-se com o mundo que a cerca. Sezici, Ocakci e Kadioglu (2017) sugerem que uma intervenção de enfermagem, mediante abordagens multidisciplinares, que pode ser por meio de brincadeiras, auxilia no desenvolvimento das habilidades sociais, emocionais e comportamentais das crianças.

O profissional de enfermagem pode buscar maneiras de minimizar o trauma de uma internação, por exemplo utilizando o brinquedo, posto que conduz o menor a vivenciar de forma menos agressiva a hospitalização e minimiza o estresse e a ansiedade decorrentes da situação vivenciada. Neste sentido, o brincar permite à criança desenvolver autoconfiança, segurança e conforto perante a equipe, uma vez que, à medida que brinca, desenvolve seu potencial psicológico e motor, conhece-se melhor, constrói o seu mundo, representa-o e prepara-se para novas experiências (JONAS et al., 2013).

De acordo com Soares et al. (2014), as brincadeiras representam um meio de alívio para as tensões que são impostas pela hospitalização e pelo estar doente. Além disso, manifestam-se como uma possibilidade de comunicação pela qual a equipe de enfermagem pode dar explicações, orientações sobre procedimentos que irão acontecer, bem como receber informações da criança em relação a como se sente e o que as situações por ela vivenciadas têm significado na sua vida.

Estudo que objetivou compreender a percepção do enfermeiro em relação ao brincar durante a assistência pediátrica em um hospital do Maranhão, desenvolvido em um hospital pediátrico do interior deste Estado, mostrou que os enfermeiros reconhecem a importância do brincar durante o internamento pediátrico, mesmo não utilizando este elemento no plano de cuidados (FERNANDES et al., 2017).

Outro ponto referido pelos participantes para a formação do vínculo é o diálogo no qual explicam os procedimentos para a criança e a família, conforme os depoimentos a seguir:

Quando muito pequenos, conversamos muito com os pais (TE4).
Converso sempre com a criança, perguntamos sobre ela [...] se vai à escola, o que ela gosta (TE2).

Converso e explico os procedimentos (TE1).

Com os maiores tenho um diálogo para estabelecer um vínculo e confiança com a criança (TE5).

Conversa-se sempre com elas (E2).

A maioria dos participantes contou que explica os procedimentos, tentando estabelecer uma relação de cuidado, e relatam que estabelecem sempre um diálogo com as crianças e os pais. Estas são iniciativas que melhoram e qualificam significativamente $o$ cuidado prestado pelos profissionais de enfermagem à criança, diminuído a ansiedade e, muitas vezes, o trauma causado pela internação.

Oliveira et al. (2015) e Gomes e Nóbrega (2015) afirmam que demostrar os equipamentos, explicar os procedimentos e dialogar com a criança e família, são formas de diminuir a ansiedade, a angústia e de criar laços entre os profissionais de enfermagem, as crianças e os pais.

O recurso lúdico torna possível o estabelecimento de um diálogo terapêutico pautado na necessidade de refletir não apenas as palavras da criança, mas os sentimentos que estão além destas, de evitar o uso de palavras de difícil compreensão, de prestar atenção ao que a criança expressa para não minimizar ou exagerar os sentimentos comunicados, evitando-se que significados sejam acrescentados ou que a sua intenção não seja compreendida (FRANCISCHINELLI; ALMEIDA; FERNANDES, 2012).

A comunicação e o vínculo são instrumentos importantes para o fortalecimento das relações na unidade de pediatria, auxiliando a família na compreensão do processo de hospitalização. Um aspecto que pode gerar conflitos é a habitual falta de oportunidade da família de expressar suas emoções e expectativas (VIEIRA, 2010).

Fornecer informações à família a respeito do processo de saúde e de doença do filho é uma ação que deve ser incorporada na prática cotidiana assistencial. A equipe de enfermagem necessita ter capacidade para exercer essa atividade a fim de estimular e auxiliar a família a adquirir confiança nas suas ações. Uma comunicação efetiva entre enfermagem, família e criança diminui a ansiedade dos pais e da criança e aumenta a aceitação e envolvimento desses no processo terapêutico. Desse modo, é possível facilitar a 
adesão ao tratamento, favorecendo o processo de enfrentamento da doença e colaborando para o crescimento (JONAS et al., 2013).

A equipe de enfermagem não deve se limitar apenas aos protocolos terapêuticos institucionais, mas também incluir ações humanizadas que valorizem a participação constante da família nesse contexto da hospitalização infantil, pois o reestabelecimento da saúde não deve ser baseado apenas no fator biológico, mas no bem-estar e qualidade de vida dessas crianças (SILVEIRA; LEGRAMANTE; PIESZAK, 2016).

Em contrapartida uma das participantes informa que apenas utiliza o diálogo quando dá tempo:

Quando dá tempo a gente conversa [...] Acho ela (abordagem lúdica) muito importante, mas deveria estar mais introjetado no nosso dia a dia [...]. Tem outro lado: a atuação do enfermeiro é muito sistemática [...] tem horário para tudo, o que impede de agir corretamente [...] mas também leva mais tempo abordar dessa maneira [...]. É bem distante da realidade, não conheço lugares que tenham isso (E2).

O depoimento faz com que se reflita sobre a perspectiva de tempo, ou melhor, sobre o que se elenca como prioridade na realização do cuidado de enfermagem. Estabelecer um diálogo cuidador pode ser a prioridade, ou o número de procedimentos realizados pode ser escolhido como prioritário. O diálogo cuidador configura-se como um diálogo em que o emissor e o receptor estão na mesma sintonia (GADAMER, 2007). Neste contexto, o profissional de saúde poderá lançar-se a este diálogo para estar cuidando da criança e família, buscando a palavra adequada, o gesto apropriado e o respeito a pessoa como ser histórico. Questiona-se, no entanto, o que os cuidadores querem realizar com o seu tempo.

Em estudo que objetivou identificar a estratégia de comunicação terapêutica mais empregada na assistência de enfermagem à criança hospitalizada, realizado em 2013, com 13 enfermeiros, 25 técnicos de enfermagem e todas as crianças atendidas na clínica pediátrica e no setor de observação pediátrica de um hospital público, os pesquisadores evidenciaram a pouca utilização das técnicas de comunicação terapêutica pela equipe de enfermagem durante a assistência, sugerindo uma maior atenção desses profissionais sobre a temática (ANDRADE et al., 2015).

Na internação pediátrica, para que os profissionais de enfermagem prestem um cuidado integral à criança, torna-se indispensável voltar a atenção para as necessidades da família, desenvolvendo um plano de cuidado centrado na díade criança e família (PACHECO et al., 2013). Neste sentido, o cuidar não se restringe à realização de uma boa técnica de enfermagem; o cuidar exige comprometimento e preocupação para com o ser humano que se pretende cuidar. Cuidar exige tempo e dedicação nesse tempo (BOFF, 2014; ROSSELÓ, 2009).

O processo de cuidar de um ser humano e, principalmente, de uma criança, é intencional e seus objetivos são variados, dependendo do momento e da situação. Por ser um processo, não deve haver preocupação com um fim (BOFF, 2014).

Sob essa ótica, realizar a abordagem da forma menos traumática para criança e família e, ao mesmo tempo, com a maior eficiência possível, deve ser a prioridade do cuidado de enfermagem à criança hospitalizada. Assim, o tempo deve ser observado pela qualidade do cuidado prestado e não pelo número de procedimentos realizados.

\section{CONCLUSÕES}

Ao buscar responder o objetivo proposto pode-se observar que a equipe de enfermagem utiliza o ato de brincar, bem como o diálogo, a fim de abordar a criança no ambiente hospitalar, com a intenção de criar vínculo e, assim, minimizar o impacto de uma internação para a criança e sua família.

Observou-se, nas falas dos participantes, a importância do vínculo e confiança como estratégias de aproximação e construção de laços afetivos com as crianças e a família. O brinquedo, por sua vez, descontrai a criança, estimulando o desempenho criativo e a sua socialização dentro do ambiente hospitalar, meIhorando a autoestima e favorecendo seu tratamento, recuperação e reabilitação.

Outro ponto mencionado é o fato de os profissionais de enfermagem seguirem regras e rotinas na instituição hospitalar, o que dificulta a abordagem por meio da brincadeira, pois há pouco tempo disponível para este tipo de abordagem, e, ainda, não faz parte da rotina hospitalar. Acredita-se, todavia, que tal abordagem pode ser utilizada pelo profissional de enfermagem sem causar danos ou atrasos nas suas demais atividades rotineiras e, ainda, prestando uma assistência integral e humanizada à criança, tornando o processo de hospitalização menos traumatizante e possibilitando uma melhor e mais rápida recuperação.

Torna-se fundamental, portanto, que os profissionais disponham de tempo para esta abordagem, compreendendo que a ciência não se sintetiza a procedimentos técnicos, mas também a promover saúde 
de maneira humanizada, o que torna a assistência às crianças mais agradável e menos dolorosa, englobando a família, que sofre também com o processo de internação do filho.

Neste sentido, sugere-se que sejam desenvolvidos estudos como este, ouvindo as famílias e a própria criança, e sejam criados projetos extencionistas nas instituições hospitalares que valorizem o lúdico, qualificando a assistência prestada à criança e sua família, bem como qualificando os profissionais de enfermagem ao atendimento humanizado.

\section{REFERÊNCIAS}

ANDRADE, K. C. S. et al. Comunicação terapêutica: instrumento básico do cuidado em crianças hospitalizadas. Revista de Enfermagem Ufpe, on-line, v. 9, n. 11, p. 9.784-9.792, 2015. Disponível em: <https://periodicos.ufpe.br/revistas/ revistaenfermagem/article/view/10769/11905>.

BOFF, L. Saber cuidar: ética do humano: compaixão pela terra. 20. ed. São Paulo: Petrópolis, RJ: Vozes, 2014.

BRITO, T. R. P. et al. As práticas lúdicas no cotidiano do cuidar em enfermagem pediátrica. Esc Anna Nery Rev Enferm, v. 13, n. 4, p. 802-808, 2009.

FARIAS, D. D. et al. A hospitalização na perspectiva da criança: uma revisão integrativa. Revista de Enfermagem Ufpe, on-line, v. 11, n. 2, p. 703-711, 2017. Disponível em: <https://periodicos.ufpe.br/revistas/revistaenfermagem/article/view/11988/14550>.

FERNANDES, M. N. F. et al. O brincar na percepção de enfermeiros em um hospital pediátrico do Maranhão. Journal of Health Sciences, v. 19, n. 2, p. 120-125, 2017.

FRANCISCHINELLI, A. G. B.; ALMEIDA, F. D. A.; FERNANDES, D. M. S. O. Uso rotineiro do brinquedo terapêutico na assistência a crianças hospitalizadas: percepção de enfermeiros. Acta Paulista de Enfermagem, v. 25, n. 1, p. 18-23, 2012.

GADAMER, H. G. Hermenêutica em retrospectiva: a posição da filosofia na sociedade. v. 4. Petrópolis: Vozes, 2007.

GOMES, G. L. L.; NÓBREGA, M. M. L. Ansiedade da hospitalização em crianças: proposta de um diagnóstico de enfermagem. Revista Latino-Americana de Enfermagem, v. 23, n. 5, p. 963-970, 2015.

JONAS, M. F. et al. O lúdico como estratégia de comunicação para a promoção do cuidado humanizado com a criança hospitalizada. Revista Brasileira de Ciências da Saúde, v. 17, n. 4, p. 393-400, 2013.

HOSTERT, P. C. D. C. P.; ENUMO, S. R. F.; LOSS, A. B. M. Brincar e problemas de comportamento de crianças com câncer de classes hospitalares. Psicologia: Teoria e Prática, v. 16, n. 1, p. 127-140, 2014.

LEE, W. S.; CHAI, P. F.; ISMAIL, Z. Impact on parents during hospitalization for acute diarrhoea in young children. Singapore Med. J., v. 53, n. 11, p. 755-759, 2012.
MAGNABOSCO, G.; TONELLI, A. L. N. F.; SOUZA, S. N. D. H. Abordagens no cuidado de enfermagem à criança hospitalizada submetida a procedimentos: uma revisão de literatura. Cogitare Enfermagem, v. 13, n. 1, p. 103-108, 2008.

MARQUES, C. D. C. et al. O cuidador familiar da criança hospitalizada na visão da equipe de enfermagem. Ciência, Cuidado e Saúde, v. 13, n. 3, p. 541-548, 2014.

MINAYO, M. C. O desafio do conhecimento: pesquisa qualitativa em saúde. 12. ed. 1a reimpressão. São Paulo: Hucitec, 2012. 407 p.

OLIVEIRA, C. S. et al. Brinquedo terapêutico na assistência à criança: percepção de enfermeiros das unidades pediátricas de um hospital universitário. Revista da Sociedade Brasileira de Enfermagem Pediátrica, v. 15, n. 1, p. 21-30, 2015.

PACHECO, S. T. D. A. et al. Cuidado centrado na família: aplicação pela enfermagem no contexto da criança hospitalizada. Revista de Enfermagem da Uerj, v. 21, n. 1, p. 106-112, 2013.

PALADINO, C. M.; CARVALHO, R.; ALMEIDA, F. A. Brinquedo terapêutico no preparo para a cirurgia: comportamentos de pré-escolares no período transitório. Revista da Escola de Enfermagem da USP, v. 48, n. 3, p. 423-429, 2014.

RIBEIRO, J. P. A ambiência como ferramenta de humanização da unidade de pediatria: contribuições da enfermagem. Rio Grande/RS - Brasil. 2015. Tese (Doutorado) - Universidade Federal do Rio Grande, Programa de Pós-Graduação em Enfermagem, 2015.

ROSSELÓ, F. T. Antropologia do cuidar. Petrópolis: Vozes, 2009.

SEZICI, E.; OCAKCI, A. F.; KADIOGLU, H. Use of Play Therapy in Nursing Process: A Prospective Randomized Controlled Study. Journal of Nursing Scholarship, v. 49, n. 2, p. 162169, 2017.

SILVEIRA, V. N.; LEGRAMANTE, M. L.; PIESZAK, G. M. A enfermagem pediátrica ante as repercussões do cuidar da criança oncológica: uma revisão de literatura. Revista Contexto \& Saúde, Ijuí: Ed. Unijuí, v. 16, n. 31, p. 34-42, 2016.

SOARES, V. A. et al. O uso do brincar pela equipe de enfermagem no cuidado paliativo de crianças com câncer. Revista Gaúcha de Enfermagem, v. 35, n. 3, p. 111-116, 2014.

SOUZA, L. P. S. et al. O brinquedo terapêutico e o lúdico na visão da equipe de enfermagem. J. Health Scilnst, v. 30, n. 4, p. 354-358, 2012.

VIEIRA, C. S. Técnicas de enfermagem em pediatria. Manual de Enfermagem em Pediatria, Goiânia, p. 139-141, 2010.

XAVIER, D. M. et al. A família na Unidade de Pediatria: convivendo com normas e rotinas hospitalares. Revista Brasileira de Enfermagem, v. 67, n. 2, p. 181-186, 2014.

. The family revealing itself as a being of rights during hospitalization of the child/La familia revelando-se como un ser de derechos durante la hospitalización del niño. Revista Brasileira de Enfermagem, v. 66, n. 6, p. 866872, 2013. 